\title{
A INFLUÊNCIA DA TRAGÉDIA NA ALEXANDRA, DE LÍCOFRON, E A QUESTÁO DA PERFORMANCE ${ }^{1}$
}

\author{
ROOSEVELT ROCHA \\ Universidade Federal do Paraná
}

\begin{abstract}
Resumo: A Alexandra, de Lícofron, é um poema helenístico no qual um mensageiro relata as profecias que ouviu Cassandra pronunciar de dentro da cela onde tinha sido presa pelo seu pai, Príamo. Nesse poema encontramos uma série de características que mostram que seu autor foi muito influenciado pela Tragédia do século $V$ a. C. Neste trabalho, pretendo examinar os elementos que caracterizam essa influência no poema e, como conclusão, pretendo tratar das possibilidades de performance de tal tipo de composição. Nos textos dos críticos mais recentes, prevalece a ideia de que a Alexandra teria sido composta para leitores eruditos do período alexandrino. Porém, quero defender a ideia de que talvez Licofron tenha composto seu poema pensando num tipo de recitação, mesmo que fosse para um público altamente preparado.
\end{abstract}

Palavras-chave: Lícofron, Tragédia, Performance.

Lícofron de Cálcis nasceu por volta de 330 a. C., na Eubeia, e morreu numa data desconhecida do século seguinte depois de trabalhar na Biblioteca de Alexandria, na época de Ptolomeu Filadelfo (285-247 a.C.), como editor dos textos da comédia grega. ${ }^{2}$ De acordo com a Suda, foi gramático e tragediógrafo, um dos sete

1 Quero agradecer ao professor Christian Werner pelo convite para participar deste número da revista Letras Clássicas em homenagem à professora Filomena Yoshie Hirata. Infelizmente, eu não tive a sorte de ser seu aluno, mas tive a ventura de encontrá-la em Congressos na Argentina e no Brasil e de ser avaliado por ela em bancas de concursos. Para mim é uma honra poder homenageá-la com uma pequena contribuição. Uma primeira versão deste texto foi apresentada em forma de comunicação livre no XVIII Congresso Nacional de Estudos Clássicos, realizado na cidade do Rio de Janeiro, de 17 a 21 de outubro de 2011.

2 Não discutirei aqui a questão da autoria ou a possibilidade de ter existido dois Lícofrons. A princípio, estou aceitando como verdadeira a hipótese de que só existiu um poeta chamado Lícofron e que ele é o autor da Alexandra. Sobre isso, ver, por exemplo, Sens, 2010, p. 302-305 e Hurst e Kolde, 2008, p. vii-xiii. 
poetas que compunham a chamada Plêiade. ${ }^{3}$ A enciclopédia bizantina nos dá títulos de vinte de suas tragédias. ${ }^{4}$ Já uma notícia transmitida por Tzetzes ${ }^{5}$ fala de 64 ou 46 tragédias. Ele compôs também um drama satírico intitulado Menedemo, em que o filósofo de Erétria, cujo nome dá o título à obra, seria a personagem principal de uma encenação jocosa. ${ }^{6}$

Porém sua obra mais famosa é o monólogo trágico intitulado Alexandra, o 'poema obscuro', segundo a Suda. Ao longo desse texto, encontramos um relato transmitido por um servo ao rei Príamo, no qual ele conta o que Cassandra (também chamada Alexandra, como seu irmão Páris era chamado Alexandros) profetizou sobre o futuro de Troia e da Hélade em geral, desde o nascimento de Páris até a época de Pirro (288-284 a. C.) e das dissenssões dos Diádocos, que só terminaram por volta de 281 a. C. ${ }^{7}$ ou de 275 a. C., quando Ptolomeu Filadelfo concluiu um tratado de amizade com os Romanos. ${ }^{8}$

$\mathrm{O}$ que pretendo fazer aqui é apresentar um breve exame dos elementos que caracterizam a influência da tragédia grega do século $\mathrm{V}$ a. C. no poema e, ao final, pretendo defender a ideia de que o poema, também por causa desse influxo da tragédia, pode ter sido apresentado num tipo de forma dramática na qual a performance estaria no limiar entre recitação e leitura dramatizada. Nos textos da crítica especializada publicados nos últimos anos, prevalece a ideia de que a Alexandra teria sido composta para ser lida por um público eminentemente erudito

3 Além de Lícofron, Alexandre da Etólia, Homero de Bizâncio, Fílico de Corcira e Sosíteo são os cinco nomes citados com mais frequência pelas fontes antigas. A eles são acrescentados, de acordo com as fontes, os nomes de Eântides, Sosífanes, Dionisiades e Eufrônio. Sobre isso, ver Cusset, 2002/3, p. 137.

4 Reproduzo aqui os textos da Suda que tratam do nosso autor:

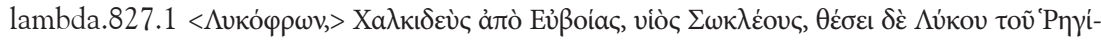
vov· $\gamma \rho \alpha \mu \mu \alpha \tau$ เ

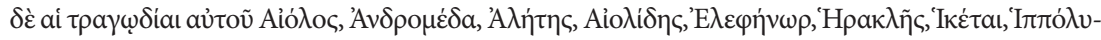

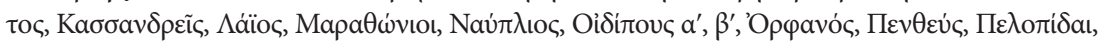

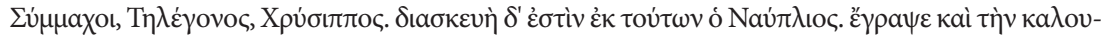

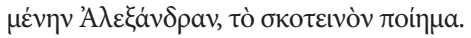

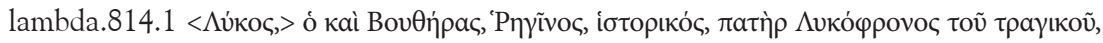

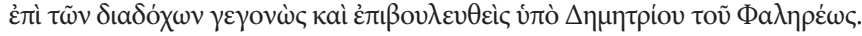

5 Ver Scheer, 1908, vol. 2, p. 4, linhas 20-21.

6 Sobre esse filósofo, ver Diógenes Laércio, 2.140; Ateneu, 2.55 e TrGF 1, p. 276-277, fr. 2-4.

7 Segundo Fenández-Galiano, 1987, p. 204-206.

8 Conforme Hurst e Kolde, 2008, p. 316-317. 
que teria convivido com Lícofron na corte de Ptolomeu Filadelfo, em Alexandria. Mesmo que fosse para um público altamente preparado, acredito que nosso poeta possa ter dado um formato dramático à sua composição, tendo em vista que, antes de Lícofron, houve outros autores que também desenvolveram um estilo obscuro e rebuscado e isso não impediu o público de apreciar suas obras.

O texto tem 1474 trímetros jâmbicos e essa já é uma característica que aproxima nosso poema da tragédia clássica em geral, pois esse era o metro usado nos diálogos nesse tipo de composição. Ademais, é interessante notar que nos versos da Alexandra encontramos pouca resolução, ou seja, a troca de uma sílaba longa por duas breves, e isso já nos indica que seu estilo tem muitos pontos de contato com o estilo de Ésquilo. Além disso, Lícofron obedece caninamente à lei de Porson, de acordo com a qual, no terceiro pé do trímetro jâmbico, quando a primeira sílaba for longa, essa sílaba e a próxima precisam ser ocupadas pela mesma palavra, a não ser que uma delas seja um monosílabo. Essa lei é seguida pelos jambógrafos do período arcaico, pelos tragediógrafos e também por Lícofron. E para mostrar como nosso poeta tem um sistema métrico rígido, comparável aos sistemas usados principalmente por Ésquilo e pelos primeiros jambógrafos, é notável o fato de que somente vinte versos da Alexandra têm mais do que doze sílabas; um único anapesto é encontrado, no verso 720, por causa da necessidade de colocar o nome de Partênope; e nunca há diérese média, ou seja, uma pausa no meio do verso, com excessão do verso 1373, porém com elisão precedendo a diérese. ${ }^{9}$

Quanto à estrutura, cabe notar primeiro que as palavras do mensageiro abrem e fecham o poema (vv. 1-30 e 1461-1474), servindo como uma espécie de enquadramento para as profecias de Cassandra, as quais constituem o núcleo do relato apresentado em primeira pessoa (vv. 31-1460), no qual o servo repete as palavras da profetiza utilizando o discurso direto e fazendo um monólogo. Desse modo, para usar a expressão de Cusset (2002/3, p. 140), do ponto ponto de vista formal, a Alexandra apresenta-se como uma hipertrofia de um relato de mensageiro.

No que diz respeito ao estilo da composição, a característica mais marcante do poema é a sua obscuridade, o que já era destacado desde a Antiguidade. Lícofron usa uma linguagem muito elaborada, com grande número de adjetivos compostos e vocabulário extremamente rebuscado, apresentando, inclusive, palavras originárias de diferentes dialetos do grego antigo e também de outras línguas. ${ }^{10}$

9 Para uma análise completa da métrica da Alexandra, ver Del Ponte, 1981.

10 Harmoi, v. 106, por exemplo, vem do siracusano; anis, v. 350, vem do beócio; ptelas, v. 833, é lacônia; ther, era usada pelos cefalônios significando 'leão'. Algumas palavras vêm 
Muitas dessas palavras ou aparecem somente na Alexandra ou são encontradas ali pela primeira vez: no léxico de Ciani (1975) encontramos 310 hapax eiremena e 104 palavras cuja primeira ocorrência é atestada em Lícofron. Nosso autor se vale constantemente de metáforas e de perífrases ao se referir a homens, deuses e lugares e esse procedimento certamente exigia uma enorme erudição da audiência, já que o poeta não usa uma linguagem direta para designar suas personagens. Pelo contrário, ele prefere usar a alusão. Além disso, em suas profecias, Cassandra menciona uma série de mitos pouco conhecidos, narrativas que não faziam parte do património mitológico pan-helênico generalizado, ou seja, histórias que circulavam em contextos limitados, como uma cidade ou região específica da Hélade. Por causa de todas essas características, a Alexandra muitas vezes foi considerada um típico produto da cultura ultra-erudita do período helenístico.

Contudo, nos últimos tempos, o poema vem despertando um novo interesse e está sendo revalorizado. ${ }^{11}$ Justamente por causa do seu nível de sofisticação e complexidade, agora ele voltou a ser objeto de estudo em muitos centros de pesquisa e se tornou tema de publicações em várias sedes. ${ }^{12}$ Há vários aspectos que tornam esse texto interessante. Em primeiro lugar, Fusillo (1984) já tinha destacado o fato de que a Alexandra ocupa uma posição fronteiriça entre o gênero épico e a tragédia. Mas quero destacar aqui a sua afinidade com a poesia trágica. Isso se torna perceptível quando vemos que Cassandra tem um envolvimento patético com aquilo que está narrando. Ela usa exclamações, faz lamentos sentidos e emprega apóstrofes, colocando-se assim no limite entre a diegesis (narrativa característica do gênero épico) e a mimesis (representação que identifica o gênero dramático). ${ }^{13} \mathrm{E}$ isso contribui para

do latim, como Neptounis, v. 1332; Graikoi nos vv. 532, 891, 1195, 1338 e Graikites no v. 605. Essas duas últimas palavras são usadas para designar os helenos, enquanto que Danaos não é empregada e Achaios aparece somente uma vez, v. 989, e Hellen também somente uma vez, v. 894. Há também exemplos provenientes da língua egípcia: phosson, v. 26; herpis, v. 579; e perra, 1428. Esses exemplos foram retirados de Fernández-Galiano, 1987, p. 33. Para mais exemplos, ver Hurst e Kolde, 2008, p. xxxvii-xxxviii.

11 Infelizmente, em português, não temos ainda nenhuma tradução e a bibliografia sobre a Alexandra é modestíssima. Até onde eu consegui verificar, em Portugal, Gonçalves (1993) e Barroso (2004) foram as únicas autoras que escreveram algo sobre nosso autor. No Brasil, só encontrei o texto de Haroldo de Campos (1976), no qual ele fala do caráter barroco do poema e apresenta uma tradução, feita com a ajuda de Francisco Achcar, de alguns versos de Lícofron. Precisamos incrementar os estudos sobre a literatura helenística no nosso país.

12 Um exemplo disso é o livro Lycophron: éclats d'obscurité, organizado por Christophe Cusset e Éveline Prioux. Ver referência completa na bibliografia, na menção a Looijenga.

13 Cf. Fantuzzi e Hunter, 2004, p. 440. 
a criação de um tipo de ilusão dramática. Embora haja grande similaridade entre a linguagem empregada pelo mensageiro no começo e no fim do poema em relação à dicção usada pela filha de Príamo, o estilo profético de Cassandra na parte central e mais extensa da Alexandra, contribui, concordando com Fountoulakis (1998, p. 293-294), para a construção de um tipo diverso de mundo imaginário e ficcional, onde a ilusão dramática criada pelo poema cativa a audiência.

O poema se apresenta como um diálogo imaginário entre o mensageiro e o rei Príamo, mas, na verdade, logo percebemos que se trata de um monólogo. Como Sens (2010, p. 300) afirma e Fantuzzi e Hunter (2004, p. 439) já tinham destacado, Lícofron utiliza a forma do relato do mensageiro, uma forma encontrada na tragédia ática em geral, estendendo-a a tal ponto que ela adquire a dimensão de uma tragédia independente. Os relatos de mensageiros, contudo, costumam contar o que aconteceu fora da cena, num passado recente, dando boas ou más notícias, geralmente em terceira pessoa. Aqui temos algo diverso: o mensageiro reproduz a voz de Cassandra, utilizando o discurso direto, ${ }^{14}$ e o seu relato diz respeito a fatos que acontecerão no futuro. Ademais, os mensageiros da tragédia fazem seus relatos para um destinatário que se encontra na orquestra, enquanto que, na Alexandra, o servo parece fazer sua narrativa para uma audiência implícita, representada pelo rei troiano, a quem é dirigida a palavra no começo e no fim do poema e que é chamado de 'mestre' e 'senhor'. Na opinião de Sens (2010, p. 300), Príamo aqui seria um espécie de dublê interno do leitor externo e talvez do patrono real de Lícofron, mas, como pretendo defender a possibilidade de algum tipo de performance para o poema, mesmo que seja uma leitura dramatizada, não posso concordar completamente com o autor. Mais adiante voltarei a essa questão.

Acredito que já tenha ficado claro que a Alexandra nao é uma tragédia: ela não tem partes para coros, não tem diálogos entre personagens e é um texto no qual o procedimento narrativo está inestricavelmente mesclado ao aspecto mimético: poderíamos dizer que é um relato construído com muitos dos elementos de um texto dramático. Porém, é evidente que Lícofron se valeu de fontes trágicas ao compor seu poema.

Já encontramos a personagem Cassandra fazendo profecias no Agamêmnon, de Ésquilo (vv. 1071-1330). E os paralelos vão além da presença dessa personagem

14 No que diz respeito ao uso do discurso direto num relato de mensageiro na tragédia, encontramos um paralelo interessante no Orestes, de Eurípides, vv. 866-952, onde o mensageiro conta o que aconteceu na assembleia, em Argos, quando foi julgado qual deveria ser o futuro de Orestes e Electra. 
nas duas obras: nosso poeta utiliza um estilo altamente esquiliano quando lança mão repetidas vezes de imagens zoológicas, que é uma das características mais notáveis da Alexandra e é algo que encontramos várias vezes no Agamêmnon. ${ }^{15} \mathrm{~A}$ cena do assassinato (vv. 1099-1119), especificamente, é um momento em que Lícofron estabelece um diálogo declarado com Ésquilo (Agamêmnon, 1382-1392), como se pode ver na tradução que apresento a seguir: ${ }^{16}$

Ele, então, no banho, buscando as saídas, difíceis de encontrar, do nó enforcapescoço 1100 na tarrafa enrolado com suas cegas mãos explorará as costuras franjeadas. E, mergulhando sob a cálida morada da banheira, manchará com seu cérebro a trípode e a bacia golpeado no meio do crânio por afiado machado. 1105 Seu lamentável fantasma voará para o Tênaro depois de ver a triste faxina da leoa. E eu jazerei perto da banheira, no chão, por calíbdica lâmina abatida depois que ela, como com tronco de pinho ou toco de carvalho 1110 um lenhador que trabalha na montanha faz, me golpear na nuca e nas costas, todo meu frio corpo despedaçando na carnificina, serpente venenosa, e depois de pisar sobre meu pescoço descarregará seu coração repleto de selvagem bile, como se eu fosse amante ilícita e não lancivencido prêmio, a ciumenta inabalável se vingando.

Como em Ésquilo, Agamêmnon é pego de surpresa enquanto toma banho. Ele tenta escapar procurando com suas mãos cegas as franjas da rede em que está envolto, mas não há saída: a rede é inextricável (aqui amphiblestron do v. 1101 ecoa o apeiron amphiblestron do v. 1382 do Agamêmnon). O rei é golpeado na cabeça com um machado pela sua esposa, que é comparada a uma leoa. É descrita também a morte de Cassandra, despedaçada por Clitemnestra como um tronco de madeira é estraçalhado por um lenhador. A intertextualidade é clara. ${ }^{17}$

15 Sobre isso, ver Cusset, 2001.

16 Todas as traduções são de minha autoria. Usei como texto de base para a Alexandra a edição de Hurst e Kolde (2008), publicada pela Sociedade de edições Les Belles Lettres, em Paris.

17 Sobre esse trecho, ver Gigante Lanzara, 2000, p. 28-29. 
Recentemente, Looijenga (2009, pp. 62-63) e Sens (2010, pp. 300-301) destacaram um outro paralelo trágico de grande interesse: o prólogo da Alexandra evoca as profecias feitas por Prometeu, no Prometeu Acorrentado, outrora atribuído a Ésquilo. Hoje em dia, poucos aceitam a autoria esquiliana dessa tragégia, mas o fato de Lícofron usar um vocabulário muito parecido com o dessa tragédia nos indica que a peça ja fazia parte do corpus canônico de Ésquilo desde o período helenístico e que o nosso poeta se coloca, através do uso da alusão, como tributário do eleusino. Basta comparar os versos de abertura da Alexandra com os versos 609. 611, do Prometeu Acorrentado:

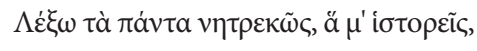

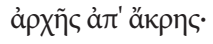

Contarei tudo que me perguntas com acribia desde o cume do começo. ${ }^{18}$

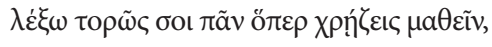

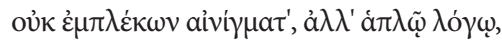


Contarei com clareza a ti tudo que queres saber, não trançando enigmas, mas com fala simples, como é justo a amigos abrir a boca. ${ }^{19}$

A similaridade vocabular mostra que Lícofron está apresentando uma variação do texto de Ésquilo. Prometeu, como Cassandra, faz um prelúdio a um extenso e detalhado relato de sofrimentos que sucederão no futuro, como comenta Sens (2010, p. 301), embora, na Alexandra, logo em seguida (vv. 3-12; ver também vv. 1462-6) o mensageiro lembre que o discurso de Cassandra foi muito confuso e difícil de entender, diferente da clareza com a qual Prometeu pretende apresentar suas profecias. Esses trechos têm muitas similaridades, mas o que vem depois, em cada um dos poemas, tem estilos diferentes e segue em direções diversas.

Outro texto onde encontramos profecias sobre os infortúnios de Agamêmnon e de Odisseu proferidas por Cassandra é a tragédia As Troianas, de Eurípides (vv. 353-405 e 424-461). Em Eurípides, contudo, a linguagem é mais simples e trans-

18 Lícofron, Alexandra, 1-2.

19 Ésquilo, Prometeu Acorrentado, 609-611. Tradução feita a partir do texto editado por Gilbert Murray e publicado em Aeschyli tragoediae, Oxford: Clarendon Press, 1955. 
parente, consoante Hurst e Kolde (2008, p. xxxi, n. 1), distante do estilo obscuro e alusivo que distingue o poema de Lícofron. Mesmo assim, embora haja essa distinção quanto à clareza do discurso em Eurípides, podemos dizer, concordando com Cusset (2002/3, p. 141), que a Alexandra é um desenvolvimento do monólogo de Cassandra nas Troianas, onde a profetisa anuncia os infortúnios futuros dos gregos e o destino dos troianos. Além disso, é interessante destacar que, à influência de Ésquilo, somase o uso de vocabulário euripidiano por Lícofron. Cusset (2002/3, p. 142-151) destaca o emprego, na Alexandra, de palavras do campo semântico do casamento e do parentesco, ${ }^{20}$ do assassinato e da destruição e da dor e do lamento, dentre as quais encontramos muitas unidades lexicais recorrentes em tragédias de Eurípides. E isso demonstra que Lícofron sofreu forte influência do autor de As Troianas também. ${ }^{21}$

Acredito já ter demonstrado o que eu queria: Lícofron sofreu forte influência da tragédia clássica do século V a. C., principalmente de Ésquilo, e isso fica claro através do estudo de uma série de características presentes na Alexandra que foram herdadas do drama ático.

Daí a nossa pergunta: sabendo dessa proximidade da Alexandra em relação à tragédia, será que o poema em questão foi apresentado através de uma performance semelhante às do teatro trágico? Cabe lembrar, mais uma vez, que a obra que estamos examinando não é uma tragédia: não temos coro e não temos diálogos entre personagens. Por seu caráter narrativo, a Alexandra estaria mais próxima do gênero épico do que do gênero dramático. Porém, como a Suda nos informa, Lícofron era um tragediógrafo, um homem do teatro, provavelmente antes de ser convidado por Ptolomeu Filadelfo para realizar a edição da comédia grega em Alexandria. Se levarmos isso em consideração, então torna-se plausível que o seu poema mais famoso e o único que sobreviveu à maré do tempo possa ter tido uma primeira ou primeiras apresentações em algum tipo de forma dramatizada.

20 Chama a atenção, por exemplo, o uso da palavra kelor, 'filho', só encontrada na Andrômaca (v. 1033), de Eurípides, e na Alexandra (vv. 495 e 1374).

21 Ver, por exemplo, no que diz respeito ao vocabulário do casamento, o uso da palavra nympheuma, no v. 935, a propósito de Admeto, e no v. 1136, numa alusão à Amazonas, também empregado por Eurípides de modo similar no v. 1204, de As Fenícias. Lícofron também teria tomado de Eurípides as palavras xuneunetos, v. 62, da Alexandra (usada na Medeia, v. 240, e no Hipólito, v. 416, com um sentido pejorativo, da mesma maneira como faz nosso autor) e homeunetos, v. 1199 (encontrada também na Medeia, v. 953, e no Íon, 894). Cf. Cusset, 2002/3, p. 142-144. Sobre a influência de Eurípides na Alexandra, ver também Gigante Lanzara, 2000, p. 29-30. 
Boa parte dos estudiosos de Lícofron julga que o texto foi composto somente para leitura. Como West (2000, p. 159) argumenta, um monólogo que tem a extensão de uma tragédia parece ser mais apropriado para a leitura privada do que para a performance diante de uma audiência. Na opinião dela, uma apresentação da Alexandra seria muito monótona e exigiria grande resistência do ator e demandaria muito esforço no que diz respeito à sua voz. Ainda de acordo com essa autora, usar um discurso de um mensageiro para relatar não ações, mas profecias proferidas em discurso direto, é algo muito artificial. Esse tipo de texto seria, desse modo, mais adequado à apreciação através da leitura. Sens (2010, p. 299) também vai nessa direção quando afirma que "a obra como um todo deve ter sido destinada a leitores eruditos e da elite mais do que para a performance para um grande público”. Sens diz que partes do poema podem ter sido selecionadas para leituras em voz alta, ${ }^{22}$ mas salienta que não há motivo para pensar que seu verdadeiro efeito só seria captado através da recitação, contrapondo-se a Fountoulakis (1998).

Bem, eu não estou de acordo com essa visão. O próprio Sens (2010, p. 297), no primeiro parágrafo do seu texto, faz um panorama acerca da sobrevivência do teatro no século IV a. C. Nessa época, as peças 'clássicas' do século V, especialmente as tragédias de Eurípides, eram reapresentadas por grupos de artistas profissionais. Sens lembra também que existem testemunhos de que as obras dramáticas do século III a. C., especificamente as obras dos poetas que faziam parte da chamada Plêiade, foram apresentadas em festivais públicos.

O principal argumento usado para descartar a possibilidade de uma performance pública da Alexandra é o fato de o poema ser muito obscuro, complexo por vários motivos e isso demandaria uma atenção e uma erudição que boa parte do público de teatro do período alexandrino não teria. Sabemos, através de uma série de estudos, que o mundo grego passou por um processo de literalização progressiva que culminou numa cultura altamente letrada e sofisticada que floresceu do século IV a. C. em diante. Porém, acredito que resquícios daquela cultura da oralidade, que foi dominante pelo menos desde o século VIII até meados do século V a. C., sobreviveram, mesmo em Alexandria, em certos contextos. E a performance teatral é uma das situações em que a oralidade continuava ativa, mesmo em épocas posteriores.

West (2000, p. 155), porém, argumenta que, no caso da Alexandra, uma apresentação ao vivo demandaria uma concentração excessiva da audiência e um

22 West (2000, p. 155) se contrapõe a essa hipótese, já que, em sua opinião, o poema tem uma estrutura muito bem pensada e ele não poderia ser apresentado de maneira satisfatória como uma série de extratos. 
esforço colossal do ator. Ela defende que o ouvinte estaria decifrando um primeiro enigma presente nas profecias de Cassandra enquanto o ator já estaria recitanto o segundo ou o terceiro. Concordo com a autora quando ela diz que seria difícil decifrar tantos enigmas acumulados num espaço tão pequeno, mas acho que é interessante notar que, em Alexandria, certamente havia um público que tinha o hábito de resolver quebra-cabeças poéticos e que apreciava esse tipo de exercício. Como Hurst e Kolde (2008, p. xxxiv) afirmam, "a Alexandria dos Ptolomeus se deliciava com os jogos de máscaras e de alusões”. Teócrito, com as Talísias e a Síringe, Calímaco, Símias, Dosíadas e Eufórion "participam de um clima intelectual marcado por um tipo de predileção pelo enigma" (Hurst e Kolde, 2008, p. xxxv). É claro que estamos falando aqui de poetas altamente eruditos e 'livrescos' que, em certos momentos, podem ter composto textos extremamente complexos e carregados de obstáculos a serem superados. E isso pode, sim, ter afastado uma parte do público. Mas, de qualquer modo, uma parte da audiência estava habituada a enfrentar o embate com esse tipo de produção poética e isso indica que havia espaço para um autor como Lícofron criar e divulgar sua obra através de algum tipo de dramatização.

De qualquer maneira, a Alexandra se inscreve numa tradição que tem suas raízes nas práticas de consulta a oráculos e profecias comuns na cultura grega: daí vem a obscuridade e a profundidade do poema (cf. Hurst e Kolde, 2008, p. xxxiii). Além disso, na própria tradição poética da Grécia Antiga nós encontramos outros autores 'difíceis' anteriores a Lícofron e que certamente demandavam do seu público muita atenção e grande intimidade com a tradição poético-mitológica da Hélade. Muitas vezes me pergunto como as pessoas conseguiam compreender, enquanto eles estavam sendo cantados e acompanhados pela dança, os poemas de Píndaro, os coros das tragédias de Ésquilo e uma obra como o nomo chamado Os Persas, de Timóteo de Mileto. Se os gregos do século V conseguiam compreender esse tipo de composição, eu acho possível que um público preparado e habituado a decifrar enigmas poéticos a todo momento tenha apreciado uma apresentação ao vivo da Alexandra. ${ }^{23}$

É preciso reconhecer: o poema é difícil de ser lido, sim. Pelo menos numa primeira leitura, num primeiro contato. Lícofron parece ter inventado muitas palavras e ele usa um vocabulário pouco comum, exótico mesmo. Nosso trabalho seria muito

23 Hurst e Kolde (2008, xxxiii) lembram que a Alexandra, na tradução de Pascal Quignard, foi apresentada em Bruxelas, em 1982. Nessa ocasião, o monólogo foi apresentado pela própria Cassandra, não pelo servo de Príamo, como seria o esperado, se os autores e executores da performance quisessem ter sido fieis ao texto. 
mais fácil se estivessem a nossa disposição todas as fontes às quais o nosso poeta faz referência e que, certamente, eram familiares ao seu público. Nós estamos em desvantagem em relação aos alexandrinos do século III a. C., pelo menos em tese.

Contudo, ao longo dos versos, percebemos que Lícofron usa repetidas vezes certas expressões (como a ap'akres do começo do poema) e palavras (como taphos, demas, gamos e pelas) ${ }^{24}$ geralmente nas mesmas posições métricas, muitas vezes criando efeitos sonoros através do uso de paronomásias, rimas e anagramas sonoros. ${ }^{25}$ Com o desenrolar da recitação, acredito que o público se acostumava com essas repetições. Isso, inclusive, seria facilitado pela regularidade do sistema métrico empregado por nosso poeta. E essas repetições, na minha opinião, funcionavam mais ou menos como balizas para a audição que dariam pistas sobre o significado daquilo que estava sendo recitado. Assim, mesmo que a audiência não compreendesse tudo, pelo menos uma parte do conteúdo lhe seria sugerido. Talvez surgisse um tipo de efeito estético resultante da recitação, algo parecido com aquilo que possivelmente acontecia quando se ouvia um oráculo ou uma profecia.

Desse modo, junto com Fountoulakis (1998, p. 294-295), defendo a ideia de que, na Alexandra, encontramos a tentativa de criação de uma atmosfera ilusória, que era característica das encenações trágicas e que a afastaria do gênero épico. Lícofron provavelmente apresentou seu poema numa forma quase-teatral, que Fountoulakis chama de Rezitationsdrama, ou seja, um tipo de recitação em público com uso apropriado de entonação e gesticulação teatral. Mas, como Fountoulakis lembra na nota 26 do seu artigo, essa hipótese não é conclusiva e está sendo colocada como uma sugestão que, contudo, deve ser levada em consideração. ${ }^{26}$

24 Só para se ter uma ideia, taphos, 'tumba' aparece 14 vezes; demas, 'corpo', 13 vezes; gamos, 'casamento', 10 vezes e pelas, 'perto', 9 vezes.

25 No fim do verso 189, por exemplo, temos a forma poton, genitivo plural de potos, significando 'bebida', 'água'. E no começo do verso seguinte temos pothon, particípio presente ativo masculino de potheo. A sequência ...poton pothon... cria um efeito sonoro interessante, que pode confundir, mas por outro lado pode servir para chamar a atenção da audiência. Outro exemplo é o jogo de troca de posições sonoras que acontece entre as palavras pelas, 'perto', e lepas, 'rochedo'. A primeira ocupa o final do verso 419 e a segunda, o final do verso 420, criando uma espécie de rima anagramática. Embora não use os metros habituais do canto, Lícofron brinca com a musicalidade das palavras.

26 Agradeço ao professor Christian Werner pela leitura de uma primeira versão deste texto e pelas inestimáveis sugestões e correções. 
REFERÊNCIAS BIBLIOGRÁFICAS

Barroso, M. S. "Cassandra: Vox feminina trágica”. Boletim de Estudos Clássicos, n . 42, Coimbra, dez. 2004, p. 199-214. Disponível em: < http://www.uc.pt/ fluc/eclassicos/publicacoes/ficheiros/BEC42/20__Maria_do_Sameiro. pdf $>$ Acesso: 27 jan. 2012.

Campos, H. "Uma Arquitextura do Barroco." In idem, A Operação do Texto, São Paulo: Perspectiva, 1976, p. 139-141 e 145-146.

Ciani, M. G. Lexikon zu Lycophron. Hildesheim: Olms, 1975.

Cusset, Christophe. "Le bestiaire de Lycophron. Entre chien et loup." Anthropozoologica 33/34, 2001, 61-72.

Cusset, Christophe. "Tragic elements in Lycophron's Alexandra." In: Jackson, S. B.; Nelis, D. P. (ed.). Studies in Hellenistic Poetry = Hermathena 173/174, 2002/03 [2005], p. 137-53.

Del Ponte, Andrea. "Lycophronis Alexandra. La versificazione e il mezzo espressivo." Studi Italiani di Filologia Classica, 53, 1981, p. 101-33.

Fantuzzi, M.; Hunter, R. Tradition and Innovation in Hellenistic Poetry. Cambridge: Cambridge University Press, 2004.

Fernández-Galiano, M.; Fernández-Galiano, E. Licofrón, Alejandra. Trifiodoro,

La toma de Ilión. Coluto, El rapto de Helena. Introd., trad. \& notas. Madrid: Gredos, 1987.

Fountoulakis, A. "On the literary genre of Lycophron's Alexandra", Acta Antiqua Hungarica, 38, 1998, p. 291-5.

Fountoulakis, A. "Lycophron. Exploring the Limits and the Constituents of Tragic Poetry” [em Grego Moderno]. In: Manakidou, F. P.; Spanoudakis, K. (ed.) Alexandrian Muse. Continuity and Innovation in Hellenistic Poetry [em Grego Moderno]. Athens: Gutenberg, 2008, p. 417-39.

Fusillo, M. "L'Alessandra di Licofrone. Racconto epico e discorso drammatico." Annali della Scuola Normale di Pisa, 14, 1984, p. 495-525.

Gigante Lanzara, V. Licofrone, Alessandra. Introduzione, traduzione e note. Milano: Biblioteca Universale Rizzoli, 2000.

Golçalves, M. I. R. "As Profecias de Cassandra." Revista da Faculdade de Letras da Universidade de Lisboa, 15, 1993, p. 23-36.

Hurst, A.; Kolde, A. Lycophron, Alexandra. Texte établi, traduit et annoté par A.H. en collaboration avec A.K. Paris: Les Belles Lettres, 2008. 
Looijenga, A. R. "Unrolling the Alexandra. The allusive messenger-speech of Lycophron's prologue and epilogue." In: Cusset, C.; Prioux, E. (ed.). Lycophron: éclats d' obscurité. Actes du colloque international de Lyon et SaintÉtienne 18-20 janvier 2007. Saint-Étienne: Publications de l'Université de Saint-Étienne, 2009 (Mémoires du Centre Jean Palerne 33), p. 59-80.

Scheer, E.. Lycophronis Alexandra. Recensuit E.S. Vol. 1: Alexandra cum paraphrasibus ad codicum fidem recensita et emendata, indices subiecti. Vol. 2: Scholia. Berlin: apud Weidmannos, 1881 \& 1908. Reprinted 1958.

Sens, A. "Hellenistic Tragedy and Lycophron's Alexandra", In: Clauss, J. J.; CUYPERS, M. (ed.). A Companion to Hellenistic Literature. Chichester \& Malden: Wiley-Blackwell, 2010, p. 297-313.

West, S. "Lycophron's Alexandra. Hindsight as Foresight Makes No Sense?" In: Depew, M.; ObBink, D. (ed.). Matrices of Genre. Authors, Canons, and Society. Cambridge (MA): Harvard UP, 2000 (Center for Hellenic Studies Colloquia), p. 153-66 and p. 284-9.

\begin{abstract}
Lycophron's Alexandra is a Hellenistic poem in which a messenger reports the prophecies that he heard Cassandra pronounce within the cell where she was arrested by his father, Priam. In this poem we find a number of features that show that its author was greatly influenced by the Tragedy of the fifth century B. C. In this paper, I intend to examine the elements that characterize this influence in the poem and, in conclusion, I want to deal with the performance possibilities of such a composition. In the most recent texts of the critics, the prevailing idea is that the Alexandra would have been written for highly educated Alexandrian readers. However, I defend the idea that perhaps Lycophron has composed his poem thinking of a sort of recitation, even if it was for a highly prepared public.
\end{abstract}

Keywords: Lycophron, Tragedy, Performance. 